\title{
UWB All-Textile Antenna with Full Ground Plane for Off-Body WBAN Communications
}

\author{
Purna B. Samal, Student Member, IEEE, Ping Jack Soh, Student Member, IEEE, \\ Guy A. E. Vandenbosch, Fellow, IEEE
}

\begin{abstract}
A fully textile microstrip topology with Ultra Wideband (UWB) characteristics useful in Wireless Body Area Networks (WBAN) is proposed. The antenna is operable within the full UWB band and incorporates a full textile shielding ground plane. The full ground plane is shown to be crucial in maintaining the performance when worn on-body. It successfully reduces any on-body performance degradation, resulting in a very robust structure. A detailed numerical and experimental evaluation of the antenna is performed in free space and on body.
\end{abstract}

Index Terms - Ultra wideband (UWB) antennas, conformal antennas, directive antennas, Wireless Body Area Network (WBAN).

\section{INTRODUCTION}

$\mathrm{T}$ he introduction of the Ultra wideband (UWB) frequency band (3.1 to $10.6 \mathrm{GHz}$ ) for commercial applications by the Federal Communication Commission (FCC) in 2002 [1] has triggered extensive research interest in realizing UWB antennas for wireless communications [2]. High data rate transmission capabilities with low power spectral densities [35] are attractive UWB features over conventional (narrow band) wireless communication techniques [6]. More recently, UWB application has been extended into the wireless body area network (WBAN) domain due to its potential in enabling worn communications [7]. In such environmental settings, the properties of the designed antenna, the comfort offered to users, and the avoidance of on-body detuning is critical in further facilitating a reliable communication link. As a consequence of these WBAN requirements, it is natural that textile-based antennas are used in order to ensure flexibility, conformality and ergonomocity [8-12].

The recently presented textile designs for wideband BAN

Manuscript received April 24, 2013. This work was supported in part by the IEEE Antenna and Propagation Society (AP-S), the EU-EXPERTS Program, the Malaysian Ministry of Education (MOE) and the Hercules Foundation.

P. B. Samal, P. J. Soh and G. A. E Vandenbosch are with the ESATTELEMIC Research Div., Dept. of Electrical Engineering, K. U. Leuven, Kasteelpark Arenberg 10, Box 2444, 3001 Leuven, Belgium. (phone: +32 16 32 1150; fax: +32 1632 1986; e-mail: pingjack.soh@esat.kuleuven.be).

P. B. Samal is on leave from the Electronics and Communication Department (ECED), College of Science and Technology, Phuntsholing, Bhutan.

P. J. Soh is on leave from the School of Computer and Communication Engineering, Universiti Malaysia Perlis (UniMAP), Pauh Putra Campus, 02600 Arau, Perlis, Malaysia. are based on monopoles and Vivaldi antennas, either fed using a microstrip line or a coplanar waveguide (CPW) [12-18]. The disadvantage of these topologies is that they generate (radiation) fields both in the forward and backward directions. This means that they inherently strongly couple to the human body when worn. In this work, an all-textile antenna with full ground plane (ATA-FGP) operable within the UWB band suited for WBAN communications is presented. Its main feature is its much improved insensitivity to the presence of the human body, thanks to the full ground plane. The innovating topology successfully implements the UWB feature in (inherently narrowband) microstrip antenna technology. Since microstrip (i.e. ground plane - patch) technology is inherently more narrowband, the fact that such a large bandwidth could be obtained is a state-of-the-art achievement.

Sections II and III discuss the details of the antenna design and its fabrication procedure. Numerical and experimental results are presented in Section IV, covering both free space (FS) and on body (OB). A repeatability and measurement robustness test is included. In Section V, the proposed ATAFGP antenna is compared with another antenna, the CPW- Fed UWB antenna without full ground plane of [19] (AW-FGP). A final conclusion is drawn in Section VI.

\section{MATERIALS AND DESIGN STRATEGY}

The materials used are Shieldit Super as conductor (for radiators and ground plane) and felt as dielectric (for the substrate). ShieldIt Super from LessEMF Inc. is a $0.17 \mathrm{~mm}$ thick, flexible conductive textile. Its conductivity is estimated using the procedure proposed in [20], resulting in a value of $1.18 \times 10^{5} \mathrm{~S} / \mathrm{m}$. Felt is a $3 \mathrm{~mm}$ thick thermally isolating material with a relative permittivity $\varepsilon_{\mathrm{r}}$ of 1.45 and a loss tangent $\tan \delta$ of 0.044 . A $50 \Omega$ SMA connector model 5463181 from RS Components is used to feed the antenna from its reverse side. The simulation tool used is the time domain solver within CST Microwave Studio [21]. During the fabrication first the patches, substrate and ground plane were dimensioned using manual cutting tools. The ShieldIt patches and ground plane were then fastened onto the felt substrate by ironing, as ShieldIt comes with a heat-activated adhesive reverse side. A through hole is created to enable the insertion of the SMA connector, and its galvanic connection to ShieldIt is enabled by soldering. ShieldIt is able to withstand ca. 250 ${ }^{\circ} \mathrm{C}$. More details of the fabrication procedure and requirements 
are provided in [20].

The design procedure is complex and is further explained at a qualitative level. First, initial dimensions of pure rectangular microstrip topologies were estimated using the well-known procedure described in [22]. Two rectangular patches were estimated to resonate at two frequency points, i.e. $5 \mathrm{GHz}$ and 7 GHz. Next, these two resonances were overlapped by integrating them in a single radiating structure. This is achieved by using a common feed line connecting the $5 \mathrm{GHz}$ patch (BC) and $7 \mathrm{GHz}$ patch (A). This already alleviates the inherent narrow band property of a microstrip topology. Then, various broadbanding techniques were used to achieve UWB characteristics [23] and to compensate for the impedance mismatch created by the inductances of the microstrip- and coaxial feed [24], while simultaneously maintaining the full ground plane. Among the techniques used are slots [17], parasitic patches [25-26], Vivaldi structures [15-16], staircases [27], and multiple resonances [28-30]. The final structure is relatively complex, and was obtained as the result of an optimization process within the solver used.

\section{Detailed DESIGN}

The final dimensions and a photo of the fabricated prototype are given in Fig. 1 (a) and (b) and Table 1. In the final topology, four top radiators can be seen. The probe feeds a small transmission line which feeds the three primary radiators $\mathrm{A}, \mathrm{B}$, and $\mathrm{C}$. Patches $\mathrm{B}$ and $\mathrm{C}$ are fed in parallel, and their combination is fed in parallel with A. An additional radiator surrounds these primary radiators and is excited solely through capacitive coupling. The operating frequencies of patches $\mathrm{A}, \mathrm{B}$, and $\mathrm{C}$ are designed to be closely-spaced, enabling a combined wideband resonance for the ATA-FGP. The respective impedances of the patches are designed accordingly. The capacitive coupling between A, B, and C and the surrounding radiator contributes to the increase of the bandwidth by properly exciting this radiator. The result is that the combined structure of patches A, B, and the parasitic patch operates from 3.4 to $7 \mathrm{GHz}$, and the higher frequency band between 7 and $10.2 \mathrm{GHz}$ is enabled through the combination of patch A and the parasitic patch. Due to their broadbanding effect, the steps and bends introduced in all patches A, B, C, and the parasitic patch are used to properly tune the frequency response and the impedance matching in order to get the required performance profile across the whole UWB band.

Since the topology is complex, incorporating numerous parameters, it is far beyond the scope of this paper to describe the effect of each of them on the performance of the structure. However, some important observations have been made during the design concerning the variation of several critical parameters, see Fig. 2. These critical parameters contribute largely in achieving the UWB behavior, trading off with the structure's complexity. The effect of each critical parameter shown in Fig. 2 is studied independently by keeping all other parameters constant. In Fig. 2(a), it is seen that a $1 \mathrm{~mm}$ minimum gap between the primary radiators and parasitic radiator yields the largest bandwidth resulting from the maximum capacitive coupling [22]. However, a minimum gap of $2 \mathrm{~mm}$ is chosen instead as the final dimension to minimize the possibility of fabrication error due to the usage of manual cutting tools. An idea of the antenna bandwidth degradation without this parasitic radiator is given in Fig. 2 (a) and labeled as WO_PAR. The effect of the horizontal feed line length $(E)$ connecting structures $\mathrm{B}$ and $\mathrm{C}$ and their corners' bending $\mathrm{b}$ on the antenna performance is shown in Fig. 2(b) and (c), respectively. The bending in Fig. 2(c) is observed to be capable in tuning the antenna between 3.4 and $6.6 \mathrm{GHz}$, whereas $E$ affects the whole frequency range.

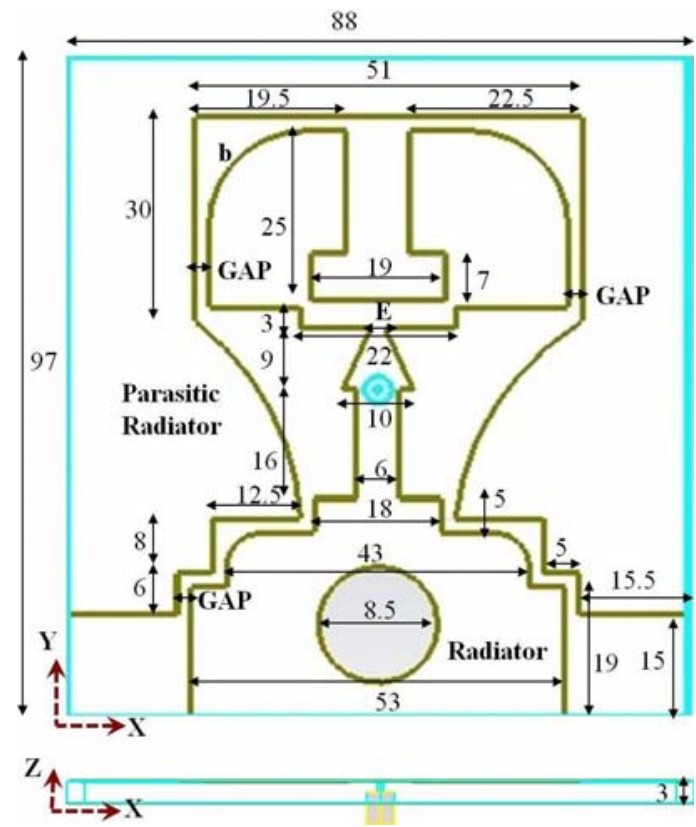

(a)

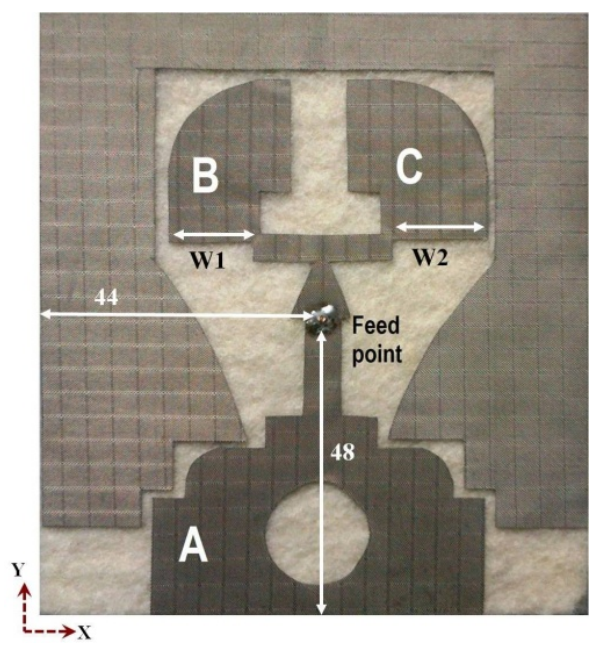

(b)

Fig. 1. (a) Dimensions of the ATA-FGP in $\mathrm{mm}$ and (b) its fabricated prototype.

TABLE I

ANTENNA PARAMETERS

\begin{tabular}{lcl}
\hline \hline Parameter & Dimension $(\mathrm{mm})$ & \multicolumn{1}{c}{ Remarks } \\
\hline Gap & 2 & $\begin{array}{l}\text { Minimum gap between main radiator } \\
\text { and parasitic radiator }\end{array}$ \\
$E(2 e)$ & $e=1$ & $\begin{array}{l}\text { Length of horizontal feed line } \\
\text { between } W 1 \text { and } W 2\end{array}$ \\
Bend $(b)$ & 14 & Bending radius of patches B and C \\
\hline \hline
\end{tabular}


Note that $W 1$ and $W 2$ are intentionally designed differently, so that the structure shows a slight asymmetry, see Fig. 1(b).

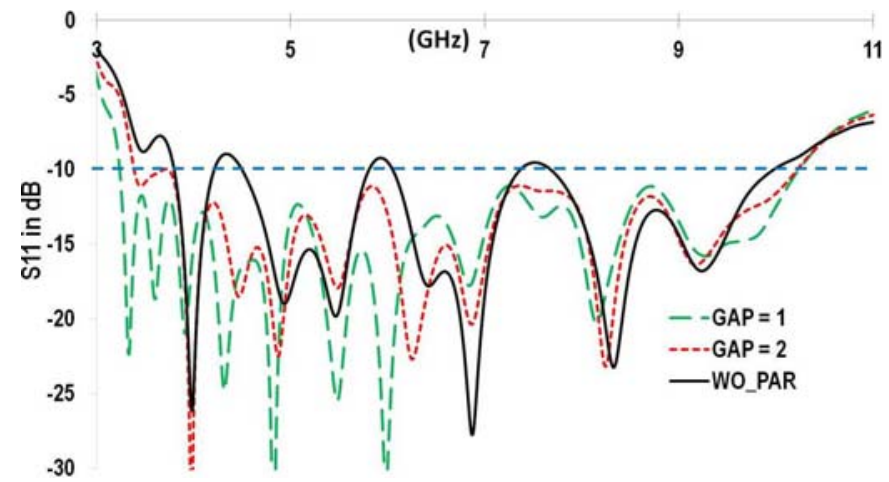

(a)

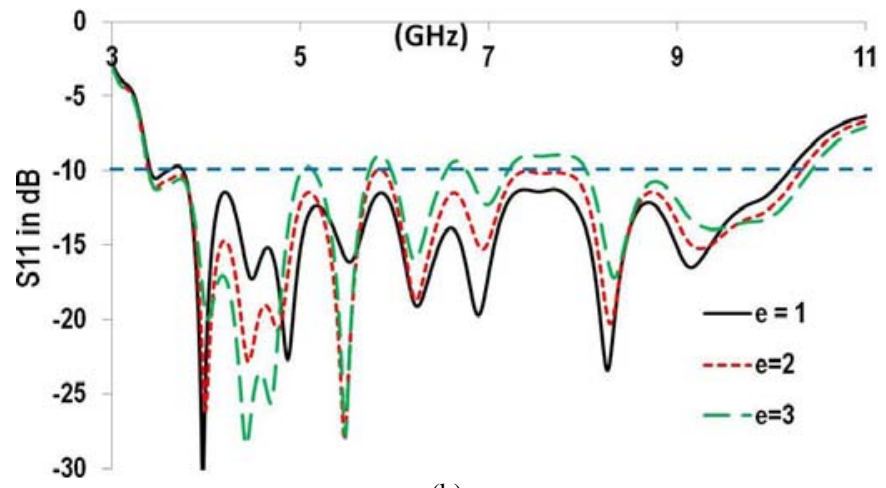

(b)

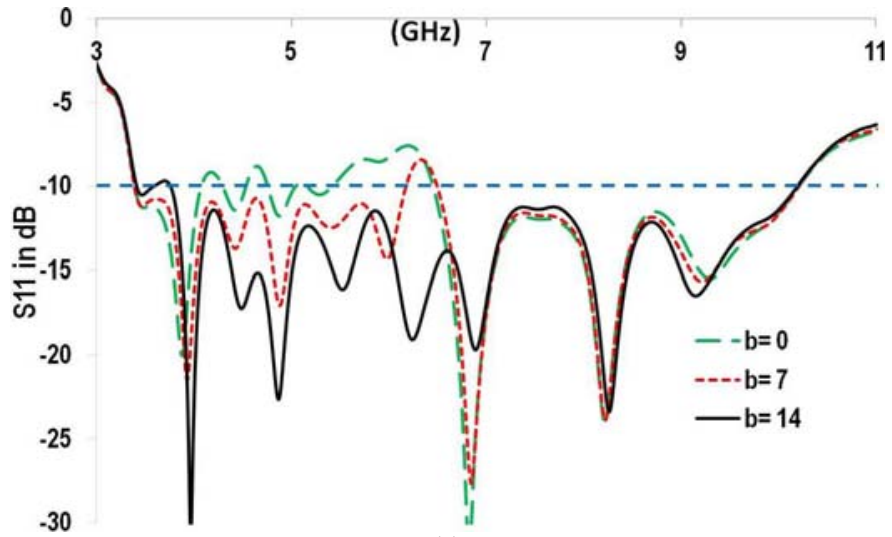

(c)

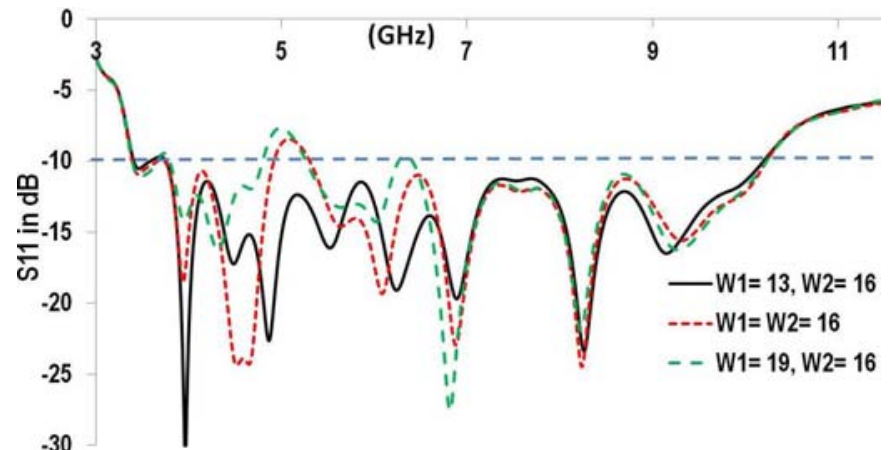

(d)

Fig. 2. Simulated $S_{11}$ with ATA-FGP's critical parameters variation: (a) top gap (GAP), (b) E, (c) bend (b) and (d) effect of dipole arm lengths (W1 and W2).
This effectively generates two closely-spaced resonances to facilitate UWB behavior at lower frequency (between 4 and 6 $\mathrm{GHz}$ ), as shown in Fig. 2(d).

\section{MEASURED RESULTS}

\section{A. Free Space}

The $S_{11}$ of the final ATA-FGP topology in free space is given in Fig. 3. The simulated $-10 \mathrm{~dB}$ bandwidth (BW) is from $3.4\left(f_{1}\right)$ to $10.2\left(f_{2}\right) \mathrm{GHz}$ and was measured to be operating from $3.6\left(\mathrm{f}_{1}{ }^{\prime}\right)$ to $10.3\left(\mathrm{f}_{2}{ }^{\prime}\right) \mathrm{GHz}$. Radiation patterns in the $\mathrm{xz}$ and yz planes are given in Fig. 4. The agreement between simulations and measurements is good.

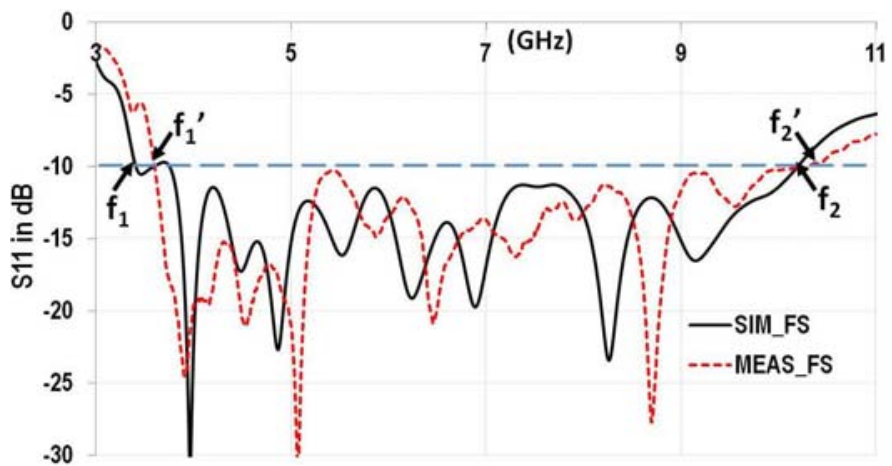

Fig. 3. Simulated and measured $S_{11}$ in FS for the prototyped ATA-FGP.
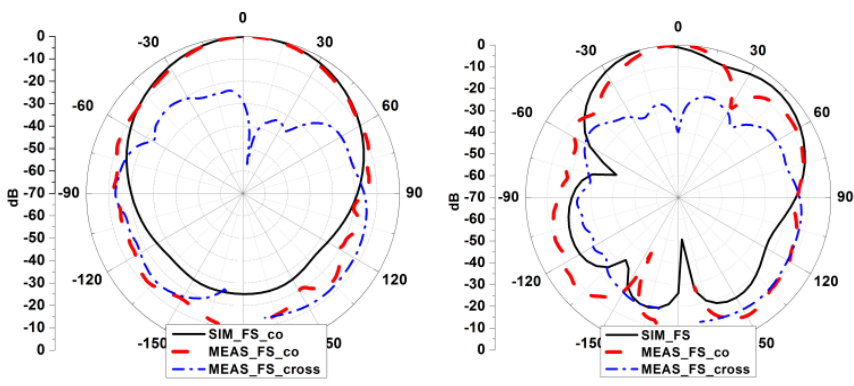

(a)

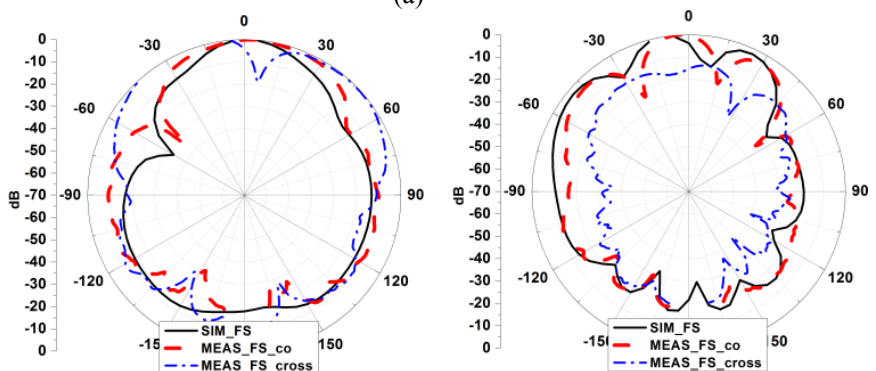

(b)
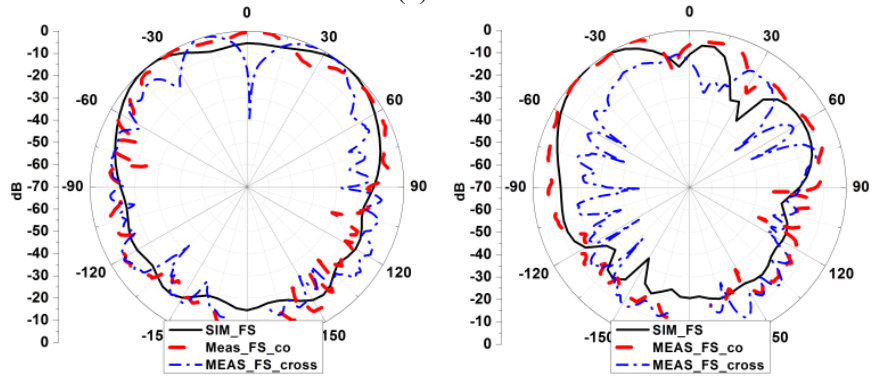

(c)

Fig. 4. Simulated and measured radiation patterns in FS in the xz plane (left) and yz plane (right) for (a) $4 \mathrm{GHz}$, (b) $7 \mathrm{GHz}$, and (c) $10 \mathrm{GHz}$. 
At $4 \mathrm{GHz}$ it is observed that the ATA-FGP exhibits a beam in the boresight direction in $\mathrm{xz}$ plane, while an omnidirectional behavior is generated in yz plane. Similar patterns are seen in both planes at 7 and $10 \mathrm{GHz}$. This is well-suited for WBAN applications [31]. The simulated and measured front-to-back ratios (FBR) at all three frequencies in FS are listed in Table 2. The simulated realized gains in FS and OB are shown in Fig. 5. The minimum gain is $1.9 \mathrm{~dB}$ at $3.6 \mathrm{GHz}$ and the maximum gain is $7.75 \mathrm{~dB}$ at $10 \mathrm{GHz}$. A comparison between simulated and measured gains at 4,7 , and $10 \mathrm{GHz}$ is given in Table 3 . The agreement is satisfactory.

\section{B. On Body $(O B)$}

For OB simulations, a simplified two-third muscle equivalent homogenous body model [31-32], sized at $131 \mathrm{x}$ $121 \mathrm{x} 44 \mathrm{~mm}^{3}$ is used. Its relative permittivity is 50.8 and its conductivity is $3 \mathrm{~S} / \mathrm{m}$. OB simulations were performed with the proposed ATA- FGP centered above this tissue model with an air gap of $10 \mathrm{~mm}$. This air gap emulates a realistic approximation of the actual placement of the ATA-FGP on a human body with clothing $[9,20]$.

TABLE II

Front to Back Ratio (IN DeCiBeLs)

\begin{tabular}{ccccc}
\hline \hline Freq $(\mathrm{GHz})$ & Plane & SIM_FS & MEAS_FS & SIM_OB \\
\hline 4 & $\mathrm{xz}$ & 25 & 12.2 & 24 \\
& $\mathrm{yz}$ & 25 & 14 & 24 \\
7 & $\mathrm{xz}$ & 18 & 20 & 32.5 \\
& $\mathrm{yz}$ & 18 & 18 & 32.5 \\
\multirow{2}{*}{10} & $\mathrm{xz}$ & 9 & 9.5 & 15 \\
& $\mathrm{yz}$ & 10 & 10 & 15 \\
\hline \hline
\end{tabular}

TABLE III

REALIZED GAIN (DB)

\begin{tabular}{cccccc}
\hline \hline $\begin{array}{c}\text { Freq } \\
(\mathrm{GHz})\end{array}$ & SIM_FS & MEAS_FS & SIM_OB & $\begin{array}{c}\text { MEAS } \\
(\text { CHEST) }\end{array}$ & $\begin{array}{c}\text { MEAS } \\
\text { (BACK) }\end{array}$ \\
\hline 4 & 6.13 & 8.07 & 6.75 & 6.31 & 6.33 \\
7 & 5.31 & 4.72 & 6.38 & 5.09 & 3.15 \\
10 & 6.98 & 5.67 & 8.34 & 6.23 & 6.89 \\
\hline \hline
\end{tabular}

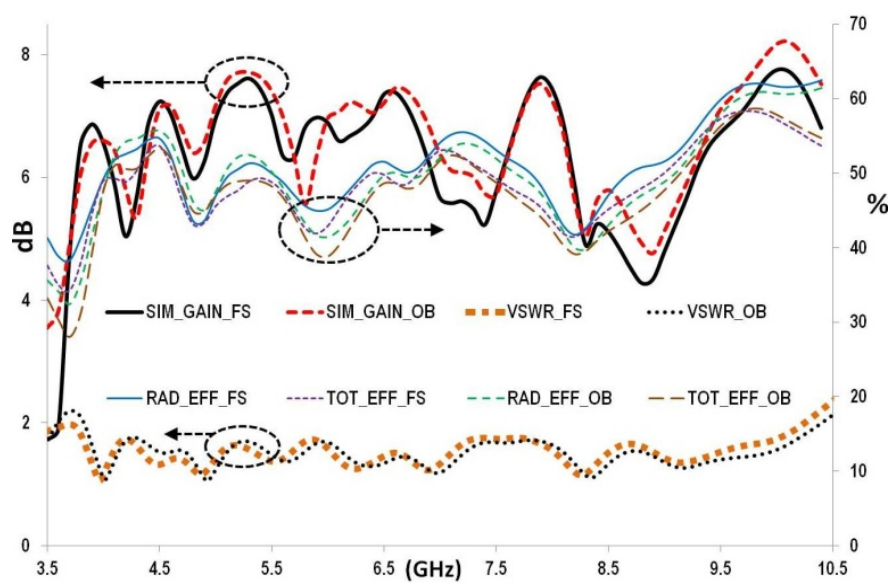

Fig. 5. Simulated gains, VWSR and efficiencies in FS and OB for the ATAFGP

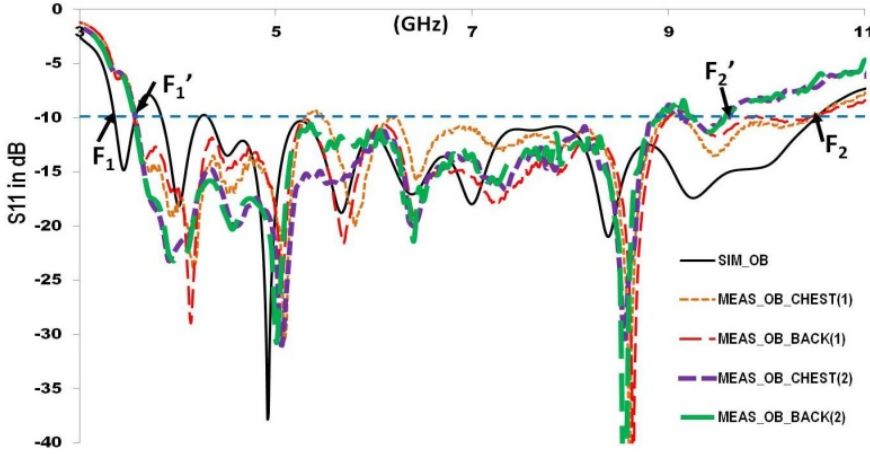

Fig. 6. Simulated and measured $S_{11} \mathrm{OB}$ (chest and back) for the proposed ATA-FGP $\left(\mathrm{F}_{1}=3.3 \mathrm{GHz}, \mathrm{F}_{2}=10.5 \mathrm{GHz}, \mathrm{F}_{1}{ }^{\prime}=3.5 \mathrm{GHz}\right.$ and $\left.\mathrm{F}_{2}{ }^{\prime}=9.6 \mathrm{GHz}\right)$
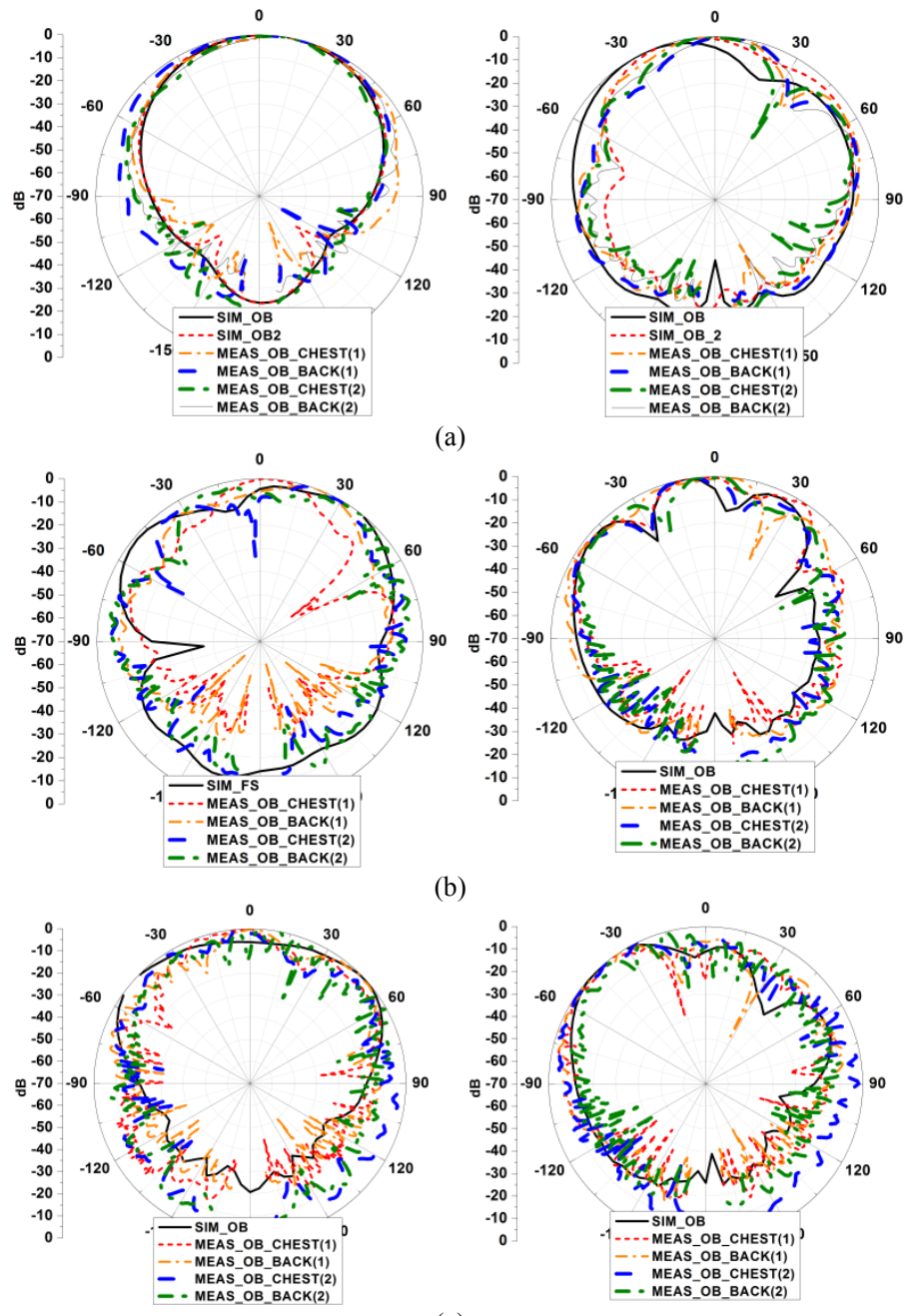

(b)

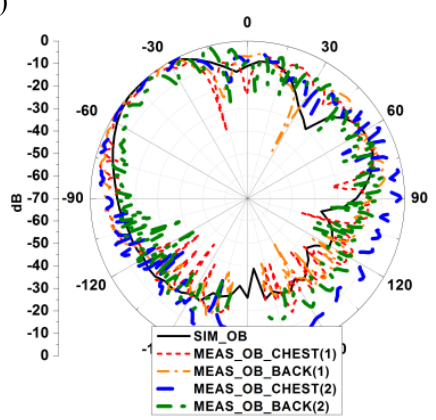

(c)

Fig. 7. Simulated and measured radiation patterns in $x z$ plane (left) and yz plane (right) for (a) $4 \mathrm{GHz}$, (b) $7 \mathrm{GHz}$, and (c) $10 \mathrm{GHz}$.

Experimental OB evaluations were performed with the ATA-FGP placed on two locations: on the chest and back of two male human volunteers in an anechoic chamber. The first volunteer (with a height of $1.58 \mathrm{~m}$ and weight of $55 \mathrm{~kg}$ ) and the second volunteer (height $1.78 \mathrm{~m}$ and weight $88 \mathrm{~kg}$ ) wore everyday clothing with ca. $5 \mathrm{~mm}$ thicknesses during evaluations to emulate practical situations. A cable-routed jacket was utilized to avoid cable movements from affecting calibration; besides ensuring consistent on-body measurement 
locations. More details of the procedure and tools are explained in [9]. Fig. 6 shows the simulated and measured $S_{11}$ for both volunteers (marked with (1) for the first and (2) for the second volunteer, respectively). Simulations agree well with measurements within the $-10 \mathrm{~dB}$ borders. It has to be emphasized that this is totally due to the presence of the full ground plane.

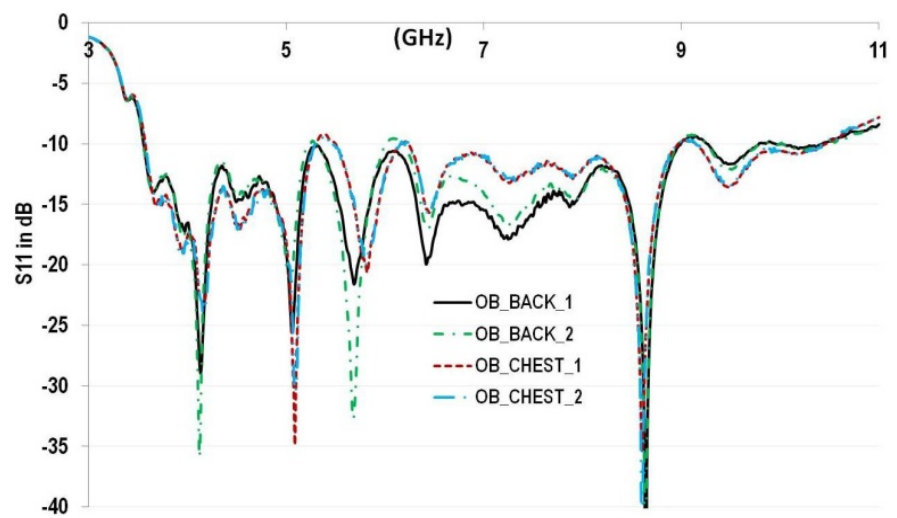

Fig. 8. Measurement repeatability for $S_{11}$ on the back and chest.

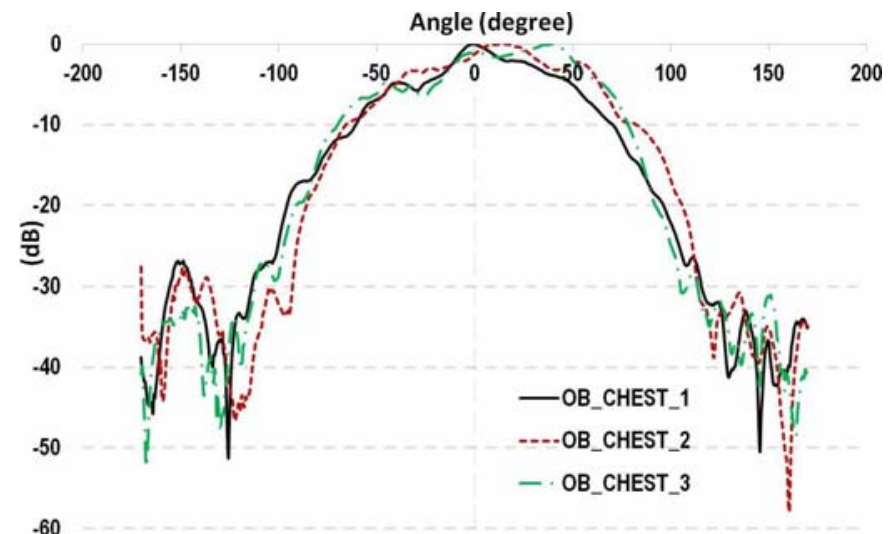

(a)

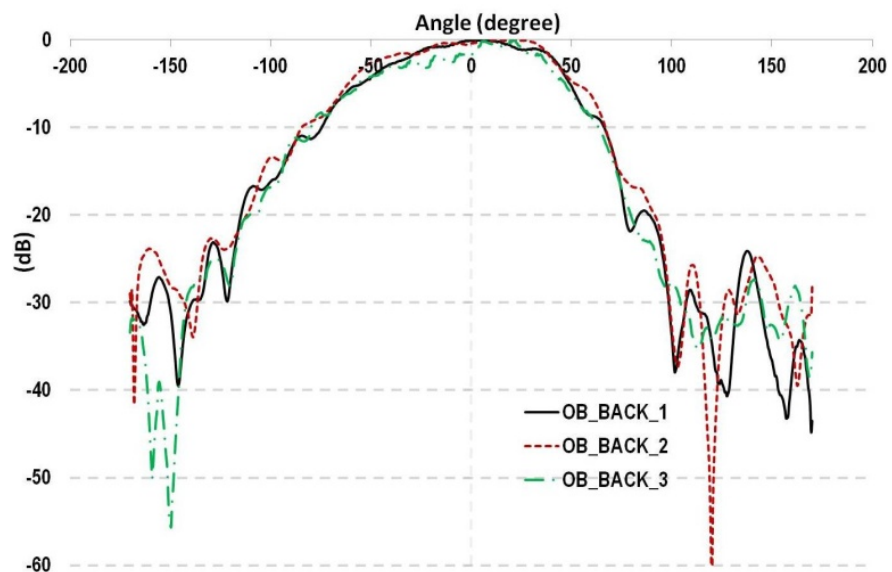

(b)

Fig. 9. Measurement repeatability for the radiation pattern in the $x z$ plane at 4 $\mathrm{GHz}$ on the (a) chest and (b) back.

Simulated and measured radiation patterns OB are shown in Fig. 7. In general simulated and measured radiation patterns show good agreement. However, due to the presence of the human body during OB evaluations, ripples are seen to occur in both $\mathrm{xz}$ and $\mathrm{yz}$ plane when $\varphi$ is beyond $\pm 60^{\circ}$. Among others, this is due to the ATA- FGP's position, which is no longer in the transmitter's line-of-sight (LOS), such that most of the received power is gathered either through reflection or diffraction. This causes the ripples in the measured $\mathrm{OB}$ radiation patterns [33]. Moreover, the human body itself acts as a reflector at higher frequencies distorting the radiation pattern [31]. This effect is observed especially at $10 \mathrm{GHz}$ with more visible ripples. A shadowing effect by the human body is also observed with sharp nulls at $7 \mathrm{GHz}$ (xz plane, $\varphi=60^{\circ}$ ) and $10 \mathrm{GHz}$ (yz plane, $\varphi=30^{\circ}$ ) [34]. On the contrary, it is obvious that such ripples and sharp nulls cannot show up in the simulated radiation patterns due to the use of a simplified, small-sized rectangular tissue model. In a first order, radiation patterns in FS and $\mathrm{OB}$ are similar, exhibiting a directive behavior at $4 \mathrm{GHz}$ and an omni-directional characteristic at 7 and $10 \mathrm{GHz}$. The simulated FBR OB is detailed in Table 2.

The realized gains for FS and OB shown in Fig. 5 are very similar, further proving the effectiveness of the full ground plane in minimizing power absorption by the body when worn by a user. These realized gains, both simulated and measured at three frequency points are presented in Table. 3. The simulated radiated efficiency (RAD_EFF) and total efficiency (TOT_EFF) for both FS and OB are shown also in Fig. 5. Placing the ATA-FGP OB resulted in a $1.6 \%$ average reduction of radiated efficiency and $1.2 \%$ reduction of total efficiency.

It is well-known that the repeatability of $\mathrm{OB}$ measurements is an issue which has to be well taken care of. The measurement robustness was checked by performing three consecutive $S_{11}$ and pattern measurements for each OB placement. The agreement seen in Fig. 8 for $S_{11}$ and in Fig. 9 for the radiation patterns confirms that the measurements are indeed repeatable. A slightly larger disagreement (by a few decibels) exists in the chest RP measurements. This is mainly caused by the chest movement due to breathing which are indeed more evident. A worse result could be expected in the case that no full ground plane would be present.

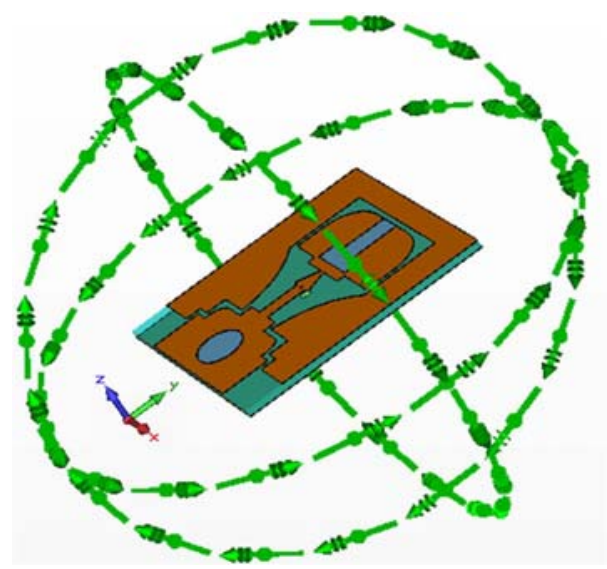

Fig. 10. Probe placement in three different planes.

Simulation of fidelity was carried out in CST Microwave studio using far field time domain probes in different planes, see Fig. 10. In each of the planes these probes were placed 
every $20^{\circ}$ at $10 \mathrm{~cm}$ from the ATA-FGP. The fidelity is computed by determining the absolute max or peak value of the cross-correlation function of the signals [35]. This was done using the default Gaussian pulse and the template based post processing in CST MWS. The fidelity results in the three planes are presented in Fig. 11. From this figure it is seen that the ATA-FGP shows a better fidelity in the xz plane with a maximum fidelity of $89.7 \%$ at $\theta=320^{\circ}$.

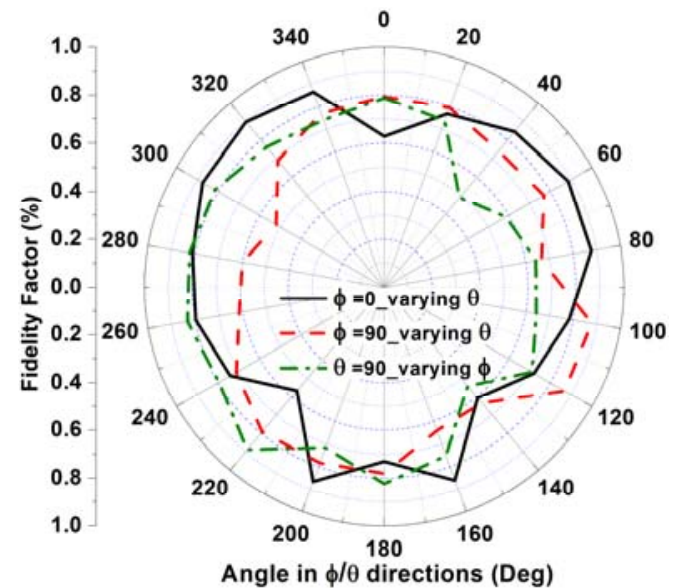

Fig. 11. Simulated fidelity in the different planes.

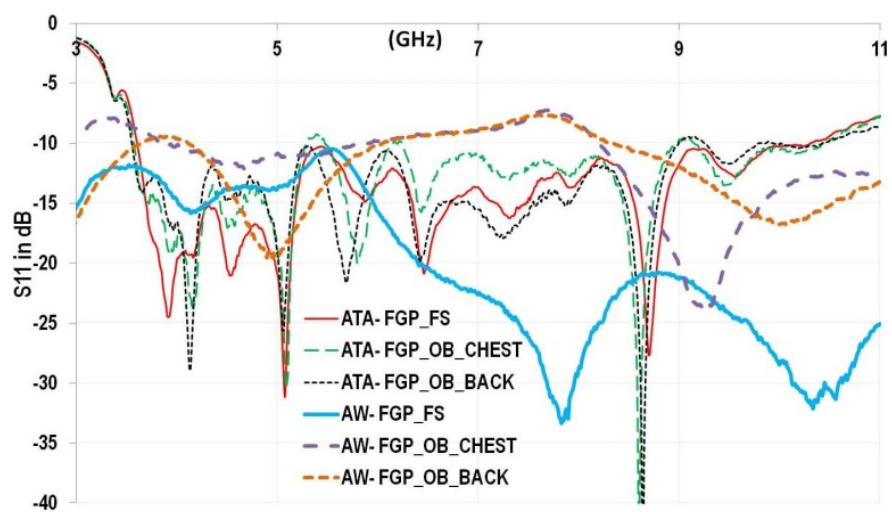

Fig. 12. Measured $S_{11}$ comparison between ATA-FGP and AW-FGP topology.

\section{EFFECT OF LARGE GROUND PLANE}

To further prove the effect of the full ground plane the ATA-FGP is compared with the flexible CPW-fed UWB antenna of [19]. The comparison is performed by evaluating $\mathrm{S}_{11}$ in both $\mathrm{FS}$ and $\mathrm{OB}$, maintaining the same environment, the same volunteer (Subject 1), and the same body locations. The results are presented in Fig. 12. It is seen that for the CPW-fed antenna, the measurements totally differ in FS and OB. This clearly illustrated that the presence of the full ground plane in the ATA-FGP successfully preserves its performance in proximity of the human body by shielding it against coupling to and power absorption by this body. Note that this shielding issue is valid for both the radiator and the feeding structure. In the ATA-FGP, with a coaxial feed, the feeding structure is completely shielded from the radiating side due to the presence of the large ground plane, and has no real effect. Meanwhile in the case of the $\mathrm{CPW}$, besides the coupling issue of the radiator itself, this feeding line also couples to both sides, which also may affect the results.

\section{CONCLUSION}

An all-textile UWB "full-ground-plane" microstrip antenna with innovating radiator topology was proposed for WBAN applications. Several broadbanding concepts were creatively combined to enable the 3 to $10 \mathrm{GHz}$ band. The proposed design is systematically evaluated both in free space and on body. A good agreement between simulations and measurements is obtained. The key innovation is the use of the quite large and full ground plane, which avoids coupling to and consequently power absorption by the human body.

\section{ACKNOWLEDGMENT}

The authors acknowledge the technical contributions by Dr. Vladimir Volskiy, Dr. Zhongkun Ma and Dr. Hadi Aliakbarian from ESAT-TELEMIC, KU Leuven.

\section{REFERENCES}

[1] FCC Report and Order for Part 15: Acceptance of Ultra Wideband (UWB) Systems from 3.1-10.6 GHz, Washington, DC, 2002.

[2] G. Z. Rafi and L. Shafai, "Wideband $V$-Slotted Diamond-Shaped Microstrip Patch Antenna," Electronics Letters, vol. 40, no. 19, pp. 1166-1167, Sept. 2004

[3] Federal Communication Commission, First Rep. Order Feb. 14, 2002

[4] B. Sanz-Izquierdo, J.C. Batchelor and M.I. Sobhy, "Compact UWB Wearable Antenna," Loughborough Antennas and Propagation Conference (LAPC 2007). pp.121-124, 2-3 April 2007.

[5] Nacer Chahat, Maxim Zhadobov, Ronan Sauleau and Koichi Ito, "A Compact UWB Antenna for On-Body Applications", IEEE Transactions on Antennas and Propagation, vol. 59, no. 4, pp.1123-1131, April 2011.

[6] K. Baskaran, C. P. Lee, C. K. Chakrabarty, "A Compact Microstrip Antenna for Ultra Wideband Applications", European Journal of Scientific Research, vol. 67, no. 1 pp. 45-51, 2011.

[7] A. Alomainy, Y. Hao, C. G. Parini, and P. S. Hall, "Comparison Between Two Different Antennas for UWB On-Body Propagation Measurements", IEEE Antennas and Wireless Propagation Letters, vol. 4, pp.31-34, 2005.

[8] P. J. Soh, G. A.E. Vandenbosch, S.L.Ooi, andM. R.N. Husna, "Wearable Dual-band Sierpinski Fractal PIFA using Conductive Fabric," Electronics Letters, vol. 47, no. 6, pp. 365-367, Mar. 2011.

[9] P. J. Soh, S. J. Boyes, G. A. E. Vandenbosch, Y. Huang, and S. L. Ooi, "On-body Characterization of a Dual-band, All-textile PIFA," Progress in Electromagnetic Research (PIER), vol. 129, pp. 517-539, 2012.

[10] S. J. Boyes, P. J. Soh, Y. Huang, G. A. E. Vandenbosch, and N. Khiabani, "On-body Performance of Dual-band Textile Antennas," IET Microwaves, Antennas \& Propagation, vol. 6, no. 15, pp. 1696-1703, Dec. 2012.

[11] Lilja, P. Salonen, T. Kaija, and P. de Maagt, "Design and Manufacturing of Robust Textile Antennas for Harsh Environments, IEEE Transactions on Antennas and Propagation, vol. 60, no. 9, pp. 4130-4140, Sept. 2012.

[12] H. K. Yoon, W. S. Kang, Y. J. Yoon, C.-H. Lee, "A CPW-fed Flexible Monopole Antenna for UWB Systems", 2007 IEEE Antennas and Propagation Society International Symposium, pp. 701-704, 9-15 June 2007.

[13] S. Gupta, M. Ramesh, A. T. Kalghatgi, "Design of Optimized CPW fed Monopole Antenna for UWB Applications", 2005 Asia-Pacific Microwave Conference Proceedings (APMC), vol. 4, pp. 4, 4-7 Dec. 2005

[14] D. Tran, F. M. Tanyer-Tigrek, A. Vorobyov, I. E. Lager, L. P. Ligthart, "A Novel CPW-fed Optimized UWB Printed Antenna", 2007 European Conference on Wireless Technologies, pp. 40-43, 8-10 Oct. 2007.

[15] M. John, M. J. Ammann, P. McEvoy, "UWB Vivaldi Antenna based on a Spline Geometry with Frequency Band-notch," 2008 IEEE Antennas and Propagation Society International Symposium (AP-S), pp. 1-4, 5-11 July 2008 .

[16] J. Bai, S. Shi, D. W. Prather," Modified Compact Antipodal Vivaldi Antenna for 4-50-GHz UWB Application", IEEE Transactions on 
Microwave Theory and Techniques, vol. 59, no. 4, pp. 1051-1057, April 2011.

[17] M. A. R. Osman, M. K. A. Rahim, M. Azfar, N. A. Samsuri, F. Zubir, K. Kamardin, "Design, Implementation and Performance of Ultrawideband Textile Antenna", Progress In Electromagnetics Research B, vol. 27 , pp. 307-325, 2011

[18] Klemm, M.; Troester, G., "Textile UWB Antennas for Wireless Body Area Networks," Antennas and Propagation, IEEE Transactions on, vol.54, no.11, pp.3192,3197, Nov. 2006

[19] P. J. Soh, G. A. E. Vandenbosch, J. Higuera-Oro, "Design and Evaluation of Flexible CPW-fed Ultra Wideband (UWB) Textile Antennas", 2011 IEEE International RF and Microwave Conference (RFM), pp. 133-136, 12-14 Dec. 2011.

[20] P. J. Soh, G. A. E. Vandenbosch, S. L. Ooi, N. H. M. Rais, "Design of a Broadband, All-textile Slotted PIFA", IEEE Transactions on Antennas and Propagation, , vol. 60, no. 1, pp. 379-384, Jan. 2012.

[21] CST Microwave Studio. ver. 2011, CST AG, Framingham, MA, USA, 2011. [Online]. Available: www.cst.com

[22] C. A. Balanis, Antenna Theory, Analysis and Design, 3rd ed. Hoboken, NJ, USA: Wiley, 2005

[23] M. Goudah, M. Y. M. Yousef, "Bandwidth Enhancement Techniques Comparison For Ultra Wideband Microstrip Antennas For Wireless Application", Journal of Theoretical and Applied Information Technology, vol. 35, no. 2, pp. 184-193, Jan. 2012.

[24] G. A. E. Vandenbosch, A. R. van de Capelle, "Study of the Capacitively Fed Microstrip Antenna Element," IEEE Transactions on Antennas and Propagation, vol. 42, no. 12, pp. 1648-1652, Dec 1994.

[25] W.-C. Liu, C.-M. Wu, Y.-J. Tseng, "Parasitically Loaded CPW-Fed Monopole Antenna for Broadband Operation", IEEE Transactions on Antennas and Propagation, vol. 59, no. 6, pp. 2415-2419, June 2011.

[26] V. G. Kasabegoudar, D. S. Upadhyay, K. J. Vinoy, "Design Studies of Ultra-Wideband Microstrip Antennas with a Small Capacitive Feed", International Journal of Antennas and Propagation, art. id. 67503, pp. 18, Oct., 2007.

[27] V. A. Shameena, S. Jacob, C.K Aanandan, K Vasudevan, P.Mohanan, "A Compact CPW fed Serrated UWB Antenna", 2011 International Conference on Communications and Signal Processing (ICCSP), pp. 108-111, 10-12 Feb. 2011.

[28] M. Koohestani, M. Golpour, "U-shaped Microstrip Patch Antenna with Novel Parasitic Tuning Stubs for Ultra Wideband Applications", IET Microwaves, Antennas \& Propagation, vol. 4, no. 7, pp. 938-946, July 2010.

[29] A. A. Abdelaziz, "Bandwidth Enhancement of Microstrip Antenna", Progress in Electromagnetics Research (PIER), vol. 63, pp. 311-317, 2006.

[30] P. Fei, Y.-C. Jiao, W. Hu, "A Compact CPW-Fed Finger-Shaped Antenna for UWB Application", 2010 9th International Symposium on Antennas Propagation and EM Theory (ISAPE), pp. 79-82, Nov. 29 2010-Dec. 2, 2010

[31] N. Chahat, M. Zhadobov, R. Sauleau, K. Ito, "A Compact UWB Antenna for On-Body Applications," IEEE Transactions on Antennas and Propagation, vol. 59, no. 4, pp. 1123-1131, April 2011.

[32] M. Klemm, I. Z. Kovcs, G. F. Pedersen, G. Troster, "Novel Small-size Directional Antenna for UWB WBAN/WPAN Applications," IEEE Transactions on Antennas and Propagation, vol. 53, no. 12, pp. 38843896, Dec. 2005.

[33] K. Watanabe, S. Hari, K. Ohno, T. Ikegami, "Experiments on Shadow Effects of Body and Effective Paths for UWB Transmission in BAN", International Symposium on Communication and Information Technologies (ISCIT) 2008, pp. 232-237, 21-23 Oct. 2008

[34] B. Ruckveratham, S. Teawehim, P. Chiochan, S. Promwong, "Evaluation of ultra wideband body area network," Biomedical Engineering International Conference (BMEiCON) 2011, pp. 311-315, 29-31 Jan. 2012

[35] A. Dumoulin, M. J. Ammann, P. McEvoy, "Performance evaluation of antennas for UWB radar and positioning systems," IET Irish Signals and Systems Conference (ISSC 2009), pp.1-6, 10-11 June 2009.

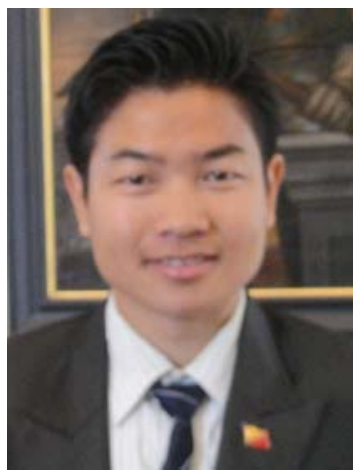

Purna B. SAMAL was born in Wangdue, Bhutan on 7 September 1984. He received Bachelor degree in Electrical Engineering from College of Science and Technology (CST), Phuentsholing, Bhutan in 2008, and the Master degree in Electrical Engineering (with a major in Eletronics and Integrated Circuits) from KU Leuven, Belgium in 2013.

Since January 2009 to date, he is an Assistant Lecturer in the Electronics and Communication Department (ECED), College of Science and Technology, Phuentsholing, Bhutan. His research interests include textile antennas, Ultra Wideband (UWB) antennas and flexible antennas for body area networks (BAN).

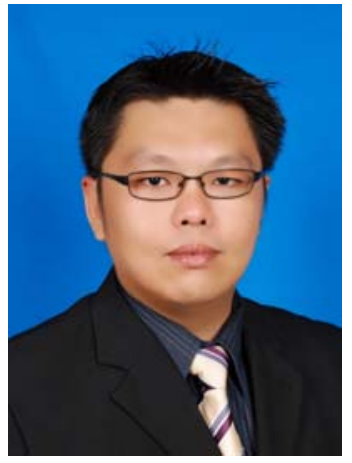

Ping Jack SOH was born in Sabah, Malaysia. $\mathrm{He}$ received the Bachelor and Master degrees in Electrical Engineering from Universiti Teknologi Malaysia (UTM), Johor, Malaysia, in 2002 and 2005, respectively.

From 2002 to 2004, he was a Test Engineer working on test definitions/procedures for the manufacturing of all-in-one printers. In 2005, he joined Motorola Technology Malaysia as a R\&D Engineer. There, he worked on the characterization and testing of new two-way radio antennas and RF front-ends. In 2006, he joined the School of Computer and Communication Engineering, Universiti Malaysia Perlis (UniMAP) as a Lecturer, and since 2011, a Senior Lecturer. $\mathrm{He}$ is currently on study leave and working towards his Ph.D in the ESATTELEMIC Research Division, K.U. Leuven, Belgium. His research interests include planar antennas, flexible/textile antennas, on-body communication, metamaterials, passive microwave components and microwave measurements.

Mr. Soh was the recipient of the CST University Publication Award in 2011 and 2012, the IEEE Antennas and Propagation Society (AP-S) Doctoral Research Award in 2012, and the IEEE Microwave Theory and Techniques Society (MTT-S) Graduate Fellowship for Medical Applications in 2013. He was also the second place winner of the IEEE Presidents' Change the World Competition in 2013.

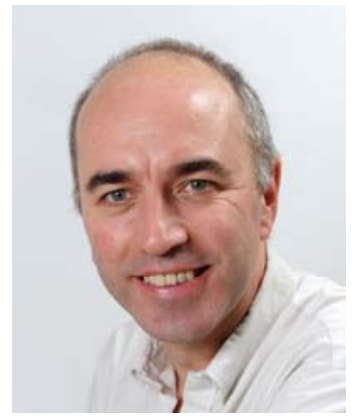

Guy A. E. VANDENBOSCH received the M.S. and Ph.D. degrees in Electrical Engineering from the Katholieke Universiteit Leuven, Leuven, Belgium, in 1985 and 1991, respectively. From 1991 to 1993 , he held a postdoctoral research position at the Katholieke Universiteit Leuven. Since 1993, he has been a Lecturer, and since 2005, a Full Professor at the same university. Guy Vandenbosch has teached or teaches courses on "Electromagnetic Waves", "Antennas", "Electromagnetic Compatibility", "Electrical Engineering, Electronics, and Electrical Energy", and "Digital Steer- and Measuring Techniques in Physics". His research interests are in the area of electromagnetic theory, computational electromagnetics, planar antennas and circuits, nano-electromagnetics, EM radiation, EMC, and bio-electromagnetics. His work has been published in ca. 185 papers in international journals and has been presented in ca. 300 papers at international conferences. Guy Vandenbosch has been a member of the "Management Committees" of the consecutive European COST actions on antennas since 1993. Within the ACE Network of Excellence of the EU (2004-2007), he was a member of the Executive Board and coordinated the activity on the creation of a European antenna software platform. At present, he leads the EuRAAP Working Group on Software and represents this group within the EuRAAP Delegate Assembly. Guy Vandenbosch is holder of a certificate of the postacademic course in Electro-Magnetic Compatibility at the Technical University Eindhoven, The Netherlands. From 2001 to 2007, he was the President of SITEL, the Belgian Society of Engineers in 
Telecommunication and Electronics. Since 2008, he is a member of the board of FITCE Belgium, the Belgian branch of the Federation of Telecommunications Engineers of the European Union. In the period 19992004, he was vice-chairman, and in the period 2005-2009 secretary of the IEEE Benelux Chapter on Antennas en Propagation. Currently he holds the position of chairman of this Chapter. In the period 2002-2004 he was secretary of the IEEE Benelux Chapter on EMC. He currently is secretary of the Belgian National Committee for Radio-electricity (URSI), where he is also in charge of commission $\mathrm{E}$. 